\title{
Strasbourg Medical Expulsion Rulings: Beyond the Deathbed Requirement
}

\author{
André den Exter \\ Erasmus Universiteit Rotterdam, Rotterdam, The Netherlands \\ denexter@law.eur.nl
}

\begin{abstract}
For decades, the European Court of Human Rights (ECtHR) has applied a restrictive interpretation on the Article 3 threshold in extradition cases. The removal of aliens from the contracting state is lawful unless the applicant faces an imminent risk of death ( $D$ v. the United Kingdom (St Kitts)). However, with the Paposhvili ruling the Court has lowered the deathbed requirement to a more favourable standard as confirmed in the latest Savran case. But will those facing medical expulsion really benefit from this new standard at national level?
\end{abstract}

\section{Keywords}

medical expulsion - threshold - severity approach - intense mental suffering Savran

\section{$1 \quad$ Introduction}

For decades, the European Court of Human Rights (ECtHR) has applied a restrictive interpretation on the Article 3 threshold in extradition cases. The removal of aliens from the contracting state is lawful unless the applicant faces an imminent risk of death due to the seriousness of his health condition and the absence of medical care in the returning country (known as the threshold of severity test in the St Kitts case). Seriously ill aliens fit to fly for removal and where there is no direct prospect of dying will not pass the 'extreme' threshold, therefore cannot claim inhuman and degrading treatment under Article 3 , and can thus be removed. 
Unexpectedly, in the Paposhvili case, the Court finally left that strict approach, lowering the threshold of severity on medical grounds (2016). Last month, that more liberal approach was confirmed in the Savran case where the applicant, facing extradition to Turkey, was diagnosed with a serious psychiatric illness and the risk of serious deterioration of his health due to the lack of necessary health care in the country of destination.

Here it is argued that the Court's latest medical refoulement cases impose a shift away from an overly restrictive exception towards a more humanitarian approach. But at national level, the Paposhvili argument appears hardly successful, at least in the Netherlands.

\section{ECtHR and Medical-related Expulsion}

\subsection{The Harsh St Kitts Approach}

In $D$ v. the United Kingdom (also known as the St Kitts case), ${ }^{1}$ the Court accepted that in very exceptional cases, the expulsion of a seriously ill alien could trigger the protection of Article 3 of the Convention on humanitarian grounds. Although states have the right to control the entry, residence and expulsion of aliens (para. 46), expulsion could nevertheless give rise to an issue under Article 3, when the person faces a real risk of being subjected to torture or inhuman and degrading treatment in the receiving country. The very exceptional circumstances of $D$ v. the United Kingdom, and the life-threatening situation due to his illness, justified granting an exception to expulsion based on medical grounds. The risk of being exposed to ill treatment in the receiving country (St Kitts), caused a severe level of suffering, far below Article 3's threshold of severity. The assessment of the minimum threshold, as confirmed in the Court's jurisprudence, includes the following circumstances:

- The severity of the illness (real and direct risk of dying). But the lifethreatening prospect itself, or decreasing life expectancy is not considered as an imminent risk (critical but stable condition, not expected to deteriorate, $N$ v. the United Kingdom).$^{2}$

- The absence of medical treatment options or medicines in the receiving country, interpreted as the availability and not financial accessibility (para. $5^{2}$ ). Not relevant is the level of medical treatment infrastructure or pharmaceutical care.

1 D v. the United Kingdom, App. no. 30240/96 (ECtHR, 2 May 1997).

$2 N$. v. the United Kingdom, App. no. 26565/05 (ECtHR [GC], 27 May 20o8), para. 47. 
- The lack of moral and social support and care by the family provided in St Kitts (para. 52).

Given these circumstances, the threshold of severity required by Article 3 requires an extreme vulnerability of the applicant, causing intense suffering contrary to human dignity. That line of reasoning has been applied on several occasions, depriving other tragic cases of medical expulsion from the benefit of the Article 3 exception. ${ }^{3}$

\subsection{The Paposhvili Test: A More Favourable Standard}

In Paposhvili v. Belgium, the applicant was facing extradition to Georgia, claiming that during imprisonment he was diagnosed with leukaemia and his health was deteriorating. ${ }^{4}$ Although considered life threatening, his vital organs were still functioning. The Chamber thus concluded that his health condition was stable and under control as a result of the treatment provided in Belgium. ${ }^{5}$ As a result he was not in imminent danger, and fit to travel. And since medication for treatment of his disease is available in Georgia, there were no exceptional circumstances precluding the applicant's removal. ${ }^{6}$ So far, the Chamber's ruling acknowledged the severity threshold as mentioned in $N$ v. the United Kingdom and there was no 'close-to-death' case. But in $N$ v. the United Kingdom the Court argued that in other very exceptional cases then 'close to death' might fall below the Article 3 minimum threshold, but it never explained what these other occasions might be. ${ }^{7}$ That was the main reason for referral to the Grand Chamber (GC), clarifying 'other very exceptional cases', as it raised 'a serious issue of general importance' that goes beyond this particular situation. ${ }^{8}$

The GC therefore continued the examination clarifying the meaning of other very exceptional cases complying with the severity threshold. According to the GC, that is the case when:

3 E.g., supra note 2: no exceptional circumstances, since the individual (HIV-infected but stable condition and under control as a result of treatment received), and his life was not in imminent danger; Bensaid v. the United Kingdom App. no. 44599/98 (ECtHR, 6 February 2001), psychiatric treatment in a hospital at a $75 \mathrm{~km}$ distance passing a 'terrorist area'; YohEkale Mwanje v. Belgium, App. no. 10486/10 (ECtHR, 20 March 2012), an advanced but not critical stage HIV patient and appropriate medication available; Tatar v. Switzerland App. no. 65692/12 (ECtHR, 14 July 2015), removal of a psychiatric patient to a country with inferior treatment facilities. All of these were seriously ill people whose condition was under control as a result of medication provided in the sending state, and who were fit to travel.

4 Paposhviliv. Belgium, App. no. 41738/10 (ECtHR [GC], 13 December 2016).

5 Ibid., 136.

6 Ibid., 137 .

7 Supra note 2, para. 43 .

8 Paposhvili, paras. 181-182; Article 43 of the Convention. 
a seriously ill person [....] would face a real risk, on account of the absence of appropriate treatment in the receiving country or the lack of access to such treatment, of being exposed to a serious, rapid and irreversible decline in his or her state of health resulting in intense suffering or to a significant reduction in life expectancy', when being removed (para. 183).

That means it is up to the applicant to provide evidence showing that there are substantial grounds, but not clear proof, that expulsion would cause such a risk contrary to Article $3 .{ }^{9}$ It is up to the state to refute any doubts about whether such a risk will appear, and 'the returning state must consider the foreseeable [health-related, $A d E]$ consequences of removal for the individual concerned in the receiving state. ${ }^{10}$ That means, that the risk assessment made by the returning state should include information from the receiving state on the availability and accessibility of health care services and medicines required in this particular case. Also, information provided by authoritative organisations such as WHO, non-governmental organisations, and the patient's medical file should be sought (para. 187).

When the applicant has provided the requested evidence, then it is for the returning state to prove that 'the medical care generally available in the receiving state is sufficient and appropriate in practice for the treatment of the applicant's illness'. It should be emphasised that the level of care provided should not be equivalent or inferior to that provided in the returning state (para. 189), but sufficient and appropriate. What is also relevant is that substantial out-ofpocket payments for medicines is considered to be a major barrier to the financial accessibility of health care, and long distances to visit health care facilities may hinder the geographical accessibility.

Finally, in case the risk assessment reveals serious doubts about the impact of removal on the person, the returning state must assure that appropriate treatment will be available and accessible to the applicant (para. 191). Otherwise, that would trigger the risk of treatment prohibited by Article 3 .

Applying the above-mentioned criteria, the GC concluded that the conditions were not satisfied. ${ }^{11}$ The information provided by the Belgian authorities appeared manifestly inadequate. Apart from the 'close to death but stable situation, and thus fit to travel' as concluded by the Belgian medical officer, none of the arguments provided by the applicant were examined by the authorities.

$9 \quad$ Ibid., 186.

$10 \quad$ Ibid., 187.

11 Ibid., 200-206. 
Since the doubts on the risk of ill treatment were not refuted, removal of the applicant to Georgia would violate Article 3.

\subsection{Savran: Confirmation and Application}

In Savran v. Denmark, ${ }^{12}$ the applicant claimed that his deportation to Turkey would be in violation of Articles 3 and 8 of the Convention. Savran entered Denmark with his family at the age of 6 (1991). In 2007, he was convicted of assault under highly aggravating circumstances. After imprisonment, in line with Danish immigration legislation he was facing deportation from Denmark. During the criminal proceedings, Savran was diagnosed with paranoid schizophrenia and a cannabis dependence syndrome. In preparation of deportation, the Immigration Service requested information on the treatment options and the availability of necessary medication in Turkey.

Fighting deportation in several instances, Savran claimed that he would not have a real possibility of receiving appropriate and necessary psychiatric treatment in Turkey, in the region of Konya. Accordingly, he would suffer a relapse and the risk and suffering would be a breach of Article 3. He referred to the medical report of his treating psychiatrist during imprisonment that in order to prevent a relapse, supervision by a regular contact person would be essential (para. 37). The government, however, concluded that the applicant could continue the same medical treatment in the Konya area, and supervised by medical staff able to communicate in the required language (Kurdish). They also observed that the $100 \mathrm{~km}$ distance to the nearest hospital would not be considered a real risk towards the availability of necessary psychiatric care. ${ }^{13}$

In its assessment, the Court repeated the Paposhvili 'very exceptional circumstances' argument in which the person would face a real risk, to be exposed to a serious, rapid and irreversible decline of health due to the absence or lack of access to the appropriate treatment (para. 45) and that such a situation, although not close to death, would cause inhuman and degrading treatment. So, prior to expulsion, the authorities of the returning state must on a case-by-case basis verify:

i. whether in practice, there is sufficient and appropriate care available to treat the applicant's disease;

\footnotetext{
12 Savran v. Denmark, App. no. 57467/15 (ECtHR, 1 October 2019).

13 Bensaid v. the United Kingdom 44599/98 (ECtHR, 6 June 2001), para. 42; Savran v. Denmark, summarised in H. Nys, 'European Court of Human Rights', European Journal of Health Law $26(5)$ (2019) 434-440, 2019/19.
} 
ii. the extent to which these health services are accessible (i.e., geographical and financial accessibility), as well as the existence of a family network for support;

iii. in case of serious doubts, whether there are adequate assurances from the receiving state about the availability and accessibility of appropriate treatment;

iv. pending expulsion, that the potential consequences of removal have been considered given the applicant's illness (paras. 46-49).

Despite the availability of psychiatric care in Turkey, the Court had some serious doubts about whether the applicant would de facto have access to appropriate medical treatment, and consequently face the deterioration in his health condition due to the risk of a psychotic relapse (para. 53). Although psychiatric treatment in general is available in Turkey, and even covered by the national health system, a follow-up and control scheme by means of a daily contact person for supervision to prevent a relapse is essential but not available; nor did the Danish authorities receive any assurances from Turkey that such outpatient therapy assistance would be available (para. 64). Since absence of appropriate psychiatric treatment would worsen his psychotic symptoms and increase the risk of aggressive behaviour, the applicant would then be exposed to a serious, rapid and irreversible decline in health, resulting in intense suffering, as concluded in Paposhvili. Such a removal would then be considered as a violation of Article 3 .

Paposhvili has been welcomed for extending the Article 3 threshold, from an 'imminent risk of dying' to 'facing a real risk [...] of being exposed to a serious, rapid and irreversible decline in his or her state of health resulting in intense suffering or to a significant reduction in life expectancy'. Although mentioned in $N$ v. the United Kingdom, only in Paposhvili did the Court clarify the meaning of 'other very exceptional cases' different from 'close to death'. Although the threshold remains high, without doubt Paposhvili means a shift the Court's medical expulsion case law. As it was ruled unanimously by the Grand Chamber, it is potentially promising for similar cases. In that respect, Savran has confirmed the very exceptional cases approach.

\subsection{Fake or Genuine Psychosis}

Still, Savran is important on its own since the Court recognises that severe mental suffering (paranoid schizophrenia) can also be interpreted as a 'very exceptional case' under the threshold; but then, only on a case-by-case review 
and taking into account the additional requirements. What is interesting is the dissenting opinion of Judge Mourou-Vikström, arguing that a mental illness is more 'volatile' and open to question, referring to the risk of a person faking psychotic symptoms, and thus lying about his mental disorder. Removal of a person with a mental disorder should therefore not be perceived in the same way as for a person with a physical disease such as leukaemia. Indeed, mental disorders may require a different approach (differentiating between genuine or malingered psychosis), but it is doubtful whether this approach should result in a higher threshold for finding a violation of Article 3 , as suggested by the dissenter. That would not be consistent with the Paposhvili approach. It is up to the court to assess the consequences of withholding antipsychotic medication, whether it would expose the applicant to 'a serious, rapid and irreversible decline of his state of health resulting in intense suffering'.

\subsection{A Less Strict Paposhvili Test?}

According to three dissenters (Judges Kjølbro, Motoc and Mourou-Vikström), the Court failed in this assessment by taking the medical experts' report for granted (the risk of pharmaceutical failure and consequently the worsening of the applicant's psychotic symptoms, and a greater risk of aggressive behaviour, para. 11) and in a way that seems correct, and thus criticises the Court's seemingly more permissive approach. But reading paragraphs 65-66 carefully, it does appear that the Court did apply the serious, rapid and irreversible decline in health test, at least implicitly. The Court recognised the seriousness of the mental disorder, qualifying the need for follow-up medical services as 'essential', in combination with the serious doubts as to the impact of removal on the applicant's health and the absent assurances of the availability of the required health services in Turkey. Under these circumstances, removal would trigger the inhuman and degrading treatment under Article 3 , by imposing the applicant to 'a serious, rapid, and irreversible decline of his health resulting in intense suffering or to a significant reduction in life expectancy'. It is therefore unlikely that the Court applied the Paposhvili rule less strictly.

\subsection{Timely, Available Medical Services?}

What's important is that the applicant has to provide evidence that appropriate treatment in this particular case is absent or de facto not available, due to the lack of essential health services, equipment or medicines, and also not financially accessible given the high costs of treatment. But 'available' could also be interpreted as available on a timely basis. If so, then what is considered as timely? It can be argued that timely means the time normally necessary for obtaining the treatment in question in the returning state, considering the applicant's current health status and the probable course of his health. More 
specifically, this means that an excessively long waiting time which is medically not justifiable, and deteriorates the patient's health condition, results in an undue delay in treatment and therefore could be interpreted as not available in practice. ${ }^{14}$ It is therefore for the applicant to provide evidence of the undue delay scenario in the returning state.

\subsection{Assurances of Appropriate Treatment}

Prior to Paposhvili, the embassy report and returning state report on the general availability of healthcare services provided sufficient evidence to conclude that there was no obstacle to medical deportation. But since Paposhvili and confirmed in Savran, that practice has appeared to be insufficient. Serious doubts about the impact of removal on the applicant's health status require 'individual and sufficient guarantees from the receiving state', that the appropriate treatment will be available and accessible. ${ }^{15}$ Apart from official observations, these assurances should be based on factual information on both the availability and accessibility of the required medical services (national reports on waiting times/lists, WHO country studies, NGO reports, etc.). Substantial financial hardship, travel distances to medical services and/or language skills may create an obstacle to the accessibility of such services, and thus need to be verified in the country report on 'appropriate treatment'. This will definitely increase the burden of proof by the sending state.

What has been the effect of Paposhvili and Savran so far at national level? Here, the focus is on one case study: the Netherlands, although not necessarily representative for other countries.

Prior to Paposhvili, the 'medical deportation' exception followed the closeto-death rule. But on 11 April 2017, the minister responsible for aliens' affairs informed the Dutch Parliament about the shift towards Paposhvili. ${ }^{16}$ Since then, other very exceptional cases might justify delaying deportation. ${ }^{17}$

In practice this means that seriously ill aliens will be granted leave to stay in case of other very exceptional circumstances, operationalised as a 'short term medical emergency'. Here, an emergency is understood as a situation in which

\footnotetext{
14 In line with CJEU ruling Case C-372/o4 Watts v. the United Kingdom, para. 57.

15 Savran, para. 48.

16 Parliamentary Letter 11 April 2017, no. 19637, no. 2312.

17 Dutch Aliens Act (Vreemdelingenwet 2000), elaborated by secondary law (Vreemdelingencirculaire 2000).
} 
the applicant, without treatment, most likely will die or suffer from invalidity or other serious mental or physical disorder within a period of a maximum of three months. ${ }^{18}$ The likeliness of death or suffering is based on contemporary medical-scientific understanding. In short, the Aliens Act exception has been extended with 'other mental and physical suffering'.

\subsection{Medical Emergency and the Judiciary}

The next question is, how has the judiciary applied the Paposhvili rule so far? As expected, no Savran references were found in the Dutch national case law database, ${ }^{19}$ but Paposhvili revealed 106 hits in total (including 22 appeal cases). Thus, since the Paposhvili ruling, courts in first instance (regional courts) and the appeal court (the Council of State) referred and applied the Paposhvili very exceptional standard test.

Still, the outcomes are quite disappointing as in all cases, the appeal court dismissed the applicant's claim of a medical emergency due to the lack of evidence. The appeal court repeatedly echoed the ECtHR's wording that 'it is for the applicant to adduce evidence capable of demonstrating that there are substantial grounds for $[\ldots]$ a real risk of being subjected to treatment contrary to Article $3 .{ }^{20}$

Such evidence should be found in the availability and accessibility of necessary health care in the destination state. According to the appeal court the mere claim that medicines are not available, or financially not accessible, remains insufficient to conclude that there are 'substantial grounds'. ${ }^{21}$ For instance, a letter provided by the applicant's treating physician about the lack of medical care in San Paulo (Brazil), or the non-confirmed statement that a certain medicine in Guinea is only available in private pharmacies and is therefore actually inaccessible, is simply inadequate. ${ }^{22}$

18 The three months period is based on providing a reliable estimation when medical treatment will be cancelled. A longer period would result in speculation, hindering the 'serious, rapid and irreversible decline in health' test.

19 See the online database, https://www.rechtspraak.nl/, accessed 1 November 2019.

20 Paposhvili, para. 186.

21 ECLI:NL:RVS:2019:983, para. 3.2 (actual accessibility medicines private clinic); ECLI: NL:RVS:2919:2392, para. 3.1; ECLI:NL:RVS:2019:988, para. 1.3; ECLI:NL:RVS:2019:987, para. 3.2; ECLI:NL:RVS:2019:986, para. 3.3; ECLI:NL:RVS:2017:2629, para. 9.1; ECLI:NL: RVS:2019:983, para. 5; ECLI:NL:RVS:2019:984, para. 3.2; ECLI:NL:RVS:2019:2739, para. 8.1; ECLI:NL:RVS:2019:571, para. 2.1; ECLI:NL:RVS:2017:1733, para. 1.7; ECLI:NL:RVS:2O19:1288, para. 4 .

22 ECLI:NL:RVS:2019:988, para. 1.4; also online Wikipedia information on the availability and accessibility of psychiatric care in Guinea, ECLI:NL:RVS:2017:2627, para. 8.2; ECLI:NL:RVS:2018:2362 evidence costs of immunodeficiency treatment, para. 5.2. 
Although no 'clear proof' is required, the threshold of evidence remains extremely high as shown by the Guinea example. According to the appeal court, the limited number of psychiatrists (five!) for the entire population does not mean that necessary psychiatric care is actually not available in Guinea. ${ }^{23}$ And since there is no reason to question the sending state's medical advisory opinion concerning the absence of medical emergency (no rapid decline in health status), the appeal failed. ${ }^{24}$

Based on the Dutch judiciary practice, one may conclude that the Paposhvili very exceptional standard has been generally accepted and applied in medical expulsion cases. But poor evidence of the factual availability and accessibility of medical services and goods provided, makes it practically impossible to comply with the rule that 'it is for the applicant to adduce evidence capable of demonstrating that there are substantial grounds for [...] a real risk of being subjected to treatment contrary to Article 3'.

Questioning the poor quality of evidence, the most likely argument is the lack of effort/time to search for more reliable information than Internet sources, medical opinions in the destination country and unfounded statements. Fact-finding by contacting (inter)national NGOS, hospitals, other health providers and WHO reports may provide a certain level of evidence required, though not 'clear proof'. In the majority of appeal cases, such information was simply absent. But even then, the Article 3 threshold remains sky-high as shown by the Guinea mental health case. Since the applicant has not been successful in providing evidence of substantial grounds of a real risk, there is no reason for the sending state to ask the destination state for assurances about the availability and accessibility of medical care.

\section{Conclusion}

In Paposhvili, the Court has 'closed the gap in the protection against inhuman treatment', as concluded by Judge Lemmens (concurring opinion). That might be true from the Convention's perspective, but at a national level a high threshold of harm remains. The Guinea case painfully shows that the very exception standard functions more as a fig leaf, which seems unrealistic to comply with, at least in The Netherlands.

23 Evidence provided by a national NGO, ECLI:NL:RVS:2019:2392, para. 5.1.
24 ECLI:NL:RVS:2019:132 para. 3.1; idem ECLI:NL:RVS:2017:2628 (risk of suicide), paras. 6.3-6.4. 